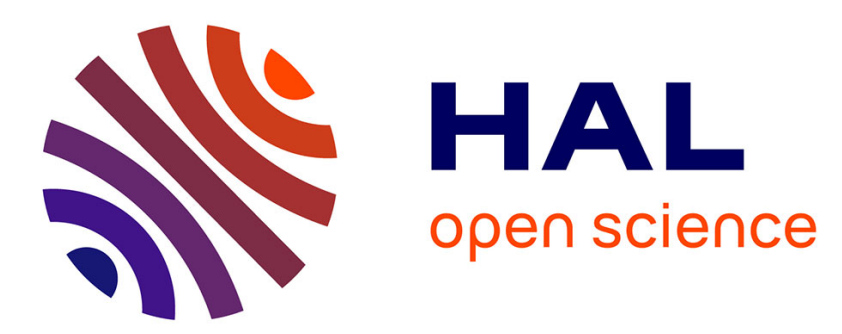

\title{
Na2VO(HPO4)2: an original phase solved by continuous 3D electron diffraction and powder X-ray diffraction
} Christophe Lepoittevin, O Leynaud, A Neveu, T Barbier, M Gnanavel, V Gopal, Valérie Pralong

\section{- To cite this version:}

Christophe Lepoittevin, O Leynaud, A Neveu, T Barbier, M Gnanavel, et al.. Na2VO(HPO4)2: an original phase solved by continuous 3D electron diffraction and powder X-ray diffraction. Dalton Transactions, 2021, 50 (28), pp.9725 - 9734. 10.1039/d1dt01548f . hal-03349467

\section{HAL Id: hal-03349467 https://hal.science/hal-03349467}

Submitted on 22 Sep 2021

HAL is a multi-disciplinary open access archive for the deposit and dissemination of scientific research documents, whether they are published or not. The documents may come from teaching and research institutions in France or abroad, or from public or private research centers.
L'archive ouverte pluridisciplinaire HAL, est destinée au dépôt et à la diffusion de documents scientifiques de niveau recherche, publiés ou non, émanant des établissements d'enseignement et de recherche français ou étrangers, des laboratoires publics ou privés. 


\title{
$\mathrm{Na}_{2} \mathrm{VO}\left(\mathrm{HPO}_{4}\right)_{2}$ : an Original Phase solved by Continuous $3 \mathrm{D}$ Electron Diffraction and Powder X-Ray Diffraction
}

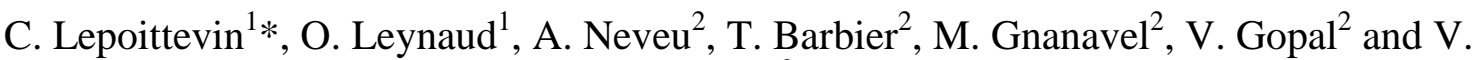 \\ Pralong ${ }^{2}$ \\ ${ }^{1}$ Université Grenoble-Alpes, Institut Néel, 25 Avenue des Martyrs-BP166, 38042 Grenoble, cedex 9 France \\ ${ }^{2}$ Normandie Univ, ENSICAEN, UNICAEN, CNRS, CRISMAT, 14000 Caen, France
}

\begin{abstract}
The new phase $\mathrm{Na}_{2} \mathrm{VO}\left(\mathrm{HPO}_{4}\right)_{2}$ was synthesized by sodium/proton ion exchange between $\mathrm{NaI}$ and $\mathrm{VO}\left(\mathrm{H}_{2} \mathrm{PO}_{4}\right)_{2}$ in hexanol. The exchange of two protons by two sodium ions causes a structural reorganization leading to a new original phase. The crystal structure was solved by continuous 3D Electron Diffraction, consisting of recording a video in diffraction mode during the continuous sample holder rotation in order to acquire a complete dataset in a shortest time in order to avoid the deterioration of this electron beam sensitive material. The individual Electron Diffraction patterns were extracted from the video, processed by conventional electron diffraction crystallography programs (PETS, JANA2006) and the resulting structural model calculated by the charge flipping algorithm was refined from powder X-ray diffraction data. This material crystallizes in an orthorhombic unit cell in the Iba2 (45) space group, with the cell parameters $\mathrm{a}=13.86852(19), \mathrm{b}=13.7985(2), \mathrm{c}=$ 7.47677(9). Electrochemical studies show that up to $0.66 \mathrm{Na} / \mathrm{f}$.u. could be removed from $\mathrm{Na}_{2} \mathrm{VO}\left(\mathrm{HPO}_{4}\right)_{2}$.
\end{abstract}

Keywords: 3D Electron Diffraction, Transmission Electron Microscopy, Cathode material, Vanadium hydrogeno phosphate, $\mathrm{Na}_{2} \mathrm{VO}\left(\mathrm{HPO}_{4}\right)_{2}$; exchange; Na-ion battery.

* Corresponding author: C. Lepoittevin 


\section{Introduction}

Transition metal phosphates are a subject of intensive research due to their electrochemical properties, which are of interest for application in metal-ion batteries. The main advantages of this family of compounds are variable oxidation states, low cost and high oxidation potential depending of the transition element. Sodium/vanadium-based phosphates are cathode materials for sodium intercalation that represent a family that has not been fully explored, in spite of promising results. Indeed, one has to mention of course the well-known Nasicon type structure with the general formula $\mathrm{A}_{\mathrm{x}} \mathrm{M}_{2}\left(\mathrm{XO}_{4}\right)_{3}$ (where $\mathrm{A}=\mathrm{Li}, \mathrm{Na} ; \mathrm{M}=\mathrm{V}, \mathrm{Fe}, \mathrm{Mn}, \mathrm{Co}$; and $\mathrm{X}$ $=\mathrm{P}, \mathrm{S}, \mathrm{W}$ ) explored for the first time by Delmas et al. ${ }^{1}$. The most representative compound of the class, $\mathrm{Na}_{3} \mathrm{~V}_{2}\left(\mathrm{PO}_{4}\right)_{3}$, acquires a 3D framework of $\mathrm{PO}_{4}$ tetrahedra and $\mathrm{VO}_{6}$ octahedra and was first studied by Yamaki et al. ${ }^{2}$. This phase shows a reversible capacity of $140 \mathrm{mAh} \mathrm{g}^{-1}$ in a voltage range of $1.2-3.5 \mathrm{~V}$ associated with the $\mathrm{V}^{4+} / \mathrm{V}^{3+}$ and $\mathrm{V}^{3+} / \mathrm{V}^{2+}$ redox couples. Due to its poor cycling stability, numerous studies have been performed in order to enhance the electronic conductivity of these materials and are reported in the reviews Advanced Sustainable Systems 2018, 1700153 ; Sustainable Energy Fuels, 2017, 1, 986-1006 ; Energy Storage Materials 7 (2017) 130-151. As for general phosphate compounds, also NASICONtype materials can be subjected to fluorination with some beneficial effects. An example is NASICON analogue $\mathrm{Na}_{3} \mathrm{~V}_{2}\left(\mathrm{PO}_{4}\right)_{2} \mathrm{~F}_{3}$, interesting for its high average voltage of $3.9 \mathrm{~V}$ and single-phase behavior with modest volume change (2\%). Another example includes $\mathrm{Na}_{1.5} \mathrm{VPO}_{4.8} \mathrm{~F}_{0.7}{ }^{3}$ which revealed excellent cycling performances, with capacities retention of $95 \%$ and $84 \%$ after 100 and 500 cycles, respectively, at 1 C. Such a promising feature has been recognized to be related to small volume change, fast $\mathrm{Na}$ diffusion $(\mathrm{Ea} \approx 0.35 \mathrm{eV})$ in $\mathrm{ab}$ plane and lack of ordered compositions within the redox window ${ }^{4}$. Furthermore, the $\mathrm{F}$ in $\mathrm{Na}_{3} \mathrm{~V}_{2}\left(\mathrm{PO}_{4}\right) \mathrm{F}_{3}$ can be substituted by oxygen to synthesize a serie of nanosized high performance cathode materials $\mathrm{Na}_{3}\left(\mathrm{VO}_{1-\mathrm{x}} \mathrm{PO}_{4}\right)_{2} \mathrm{~F}_{1+2 \mathrm{x}}(0 \leq \mathrm{x} \leq 1)^{5,6}$ by a novel solvothermal lowtemperature $\left(60-120^{\circ} \mathrm{C}\right)$ approach without the use of organic ligands or surfactants. Taking $\mathrm{Na}_{3}\left(\mathrm{VOPO}_{4}\right)_{2} \mathrm{~F}$ as a representative compound, which exhibits an extraordinary cycling performance with $90 \%$ capacity retention over 1200 cycles at $2 \mathrm{C}$ rate. Another sodium/vanadium based phosphate have been also reported by Deriouch et al ${ }^{7} ; \mathrm{Na}_{4} \mathrm{VO}\left(\mathrm{PO}_{4}\right)_{2}$ is showing a reversible capacity of one sodium at $3.4 \mathrm{~V}$. The best performances have been obtained on vanadium based pyrophosphates such as $\mathrm{Na}_{2} \mathrm{VOP}_{2} \mathrm{O}_{7}{ }^{8}$ or $\mathrm{Na}_{7} \mathrm{~V}_{4}\left(\mathrm{P}_{2} \mathrm{O}_{7}\right)_{4} \mathrm{PO}_{4}{ }^{9,10}$. All these above materials are showing modest capacity due to heavy polyanions groups despite an interesting operating voltage around $3.8 \mathrm{~V}$. Note therefore that very few sodium vanadium hydrogeno-phosphate have been reported in the literature, one can cite for example the two compositions: $\mathrm{Na}_{3} \mathrm{VOH}\left(\mathrm{HPO}_{4}\right) \mathrm{PO}_{4}{ }^{11}$ and $\mathrm{Na}_{3} \mathrm{VO}\left(\mathrm{HPO}_{4}\right) \mathrm{PO}_{4}{ }^{12}$ reported in the literature.

Based on the above observations, we believe that the research of new sodium/vanadium based phosphate offers a wide field for the discovery of cathode materials. We report herein on a new sodium vanadyl hydrogen-phosphate $\mathrm{Na}_{2} \mathrm{VO}\left(\mathrm{HPO}_{4}\right)_{2}$ that has been synthesized from the acidic vanadyl phosphate $\mathrm{VO}\left(\mathrm{H}_{2} \mathrm{PO}_{4}\right)_{2}$ by ion exchange method.

Since the crystal structure could not be solved ab initio from the powder X-ray diffraction data, Electron Diffraction has been chosen as a method of choice for this study. Over the past decade electron diffraction has become a solid alternative to X-ray or neutron diffraction for solving $a b$ initio crystal structure. The possibility to exploit electron diffraction intensities started with the discovery of precession electron diffraction, allowing a significant reduction of the dynamical effects ${ }^{13}$, followed by the development of 3D Electron Diffraction (3D ED). 3D ED was developed in $2007^{14}$ and is now considered as a routine method in ab initio crystal 
structure determination. As few examples proving the efficiency of this method, complex commensurate ${ }^{15}$ or incommensurate ${ }^{16}$ modulated structures have been successfully solved, as well as the detection of light elements such as $\mathrm{Li}$ in $\mathrm{Mn} / \mathrm{Fe}$ phosphates cathode materials ${ }^{17}$ or more spectacularly hydrogen in cobalt aluminophosphate single nanocrystals by combining with dynamical refinement ${ }^{18}$. In this paper the crystal structure solution of $\mathrm{Na}_{2} \mathrm{VO}\left(\mathrm{HPO}_{4}\right)_{2}$ by continuous 3D ED is described, the challenge in this work being to be able to record a complete dataset only in a few minutes in order to prevent the material damage under the electron beam.

\section{Experimental}

The vanadium phosphate $\mathrm{VO}\left(\mathrm{H}_{2} \mathrm{PO}_{4}\right)_{2}$ was synthesized as previously described ${ }^{19}$ by the reaction of $\mathrm{V}_{2} \mathrm{O}_{3}$ with an excess of concentrated $\mathrm{H}_{3} \mathrm{PO}_{4}$ solution at $170{ }^{\circ} \mathrm{C}$ following the equation (1):

$$
\mathrm{V}_{2} \mathrm{O}_{3(\mathrm{~s})}+4 \mathrm{H}_{3} \mathrm{PO}_{4(\mathrm{l})} \rightarrow 2 \mathrm{VO}\left(\mathrm{H}_{2} \mathrm{PO}_{4}\right)_{2(\mathrm{~s})}+\mathrm{H}_{2} \mathrm{O}_{(\mathrm{l})}+\mathrm{H}_{2}(\mathrm{~g})
$$

This solution was stirred for 24 hours at $170{ }^{\circ} \mathrm{C}$, leading to the formation of a light blue color precipitate. Thus, the precipitate was centrifuged and washed several times with acetone and then dried at $60{ }^{\circ} \mathrm{C}$ in air.

The ionic exchange of $\mathrm{Na}^{+}$with $\mathrm{H}^{+}$in the acidic vanadium phosphate $\mathrm{VO}\left(\mathrm{H}_{2} \mathrm{PO}_{4}\right)_{2}$ was performed in the following way: typically, $0.5 \mathrm{~g}$ of $\mathrm{VO}\left(\mathrm{H}_{2} \mathrm{PO}_{4}\right)_{2}$ was refluxed with excess amount of $\mathrm{NaI}$ dissolved in $20 \mathrm{ml}$ of hexanol at $150^{\circ} \mathrm{C}$ for 6 days. The ion exchanged product was centrifuged and washed several times with ethanol followed by acetone and dried in air overnight at $60^{\circ} \mathrm{C}$. The exchange is following the equation (2):

$$
\mathrm{VO}\left(\mathrm{H}_{2} \mathrm{PO}_{4}\right)_{2(\mathrm{~s})}+2 \mathrm{NaI}_{(\mathrm{s})} \rightarrow \mathrm{Na}_{2} \mathrm{VO}\left(\mathrm{HPO}_{4}\right)_{2}(\mathrm{~s})+2 \mathrm{HI}(\mathrm{l})
$$

Identification of the crystalline phases, as well as structural refinements were carried out from Powder X-Ray Diffraction (PXRD), using a Bruker D8 Advance two-circle diffractometer ( $\theta$ $2 \theta$ Bragg Brentano mode) with $\mathrm{Cu} \mathrm{K}_{\alpha 1}$ radiation $(\lambda=1.540598 \AA$ ), a Ge (111) monochromator (Johansson type) and a Lynx-Eye linear detector. Data were collected over the angular range of $10^{\circ}<2 \theta<100$, and consist of the sum of six 6 hours patterns. The instrumental contribution to the peak profile has been determined from a $\mathrm{LaB}_{6}$ standard and the resulting instrument resolution file subsequently used for LeBail $^{20}$ and Rietveld ${ }^{21}$ refinements. A Thompson-Cox-Hastings pseudo-Voigt profile function ${ }^{22}$ was selected to fit peak profile; all refinements were performed using FullProf and WinPlotr software packages $^{23,24}$. Whole pattern LeBail refinements were refined with zero shift correction for sample height, asymmetry parameters and sample broadening contribution. Background points were hand selected. For Rietveld refinements, the scale factor, a global isotropic thermal parameter, and atomic positions (except for hydrogen atoms) were added to the refined parameters.

For the transmission electron microscopy (TEM) analysis, the specimen was prepared by crushing a small amount of sample in an agate mortar containing ethanol, and a drop of the suspension was deposited on a holey carbon membrane supported by a copper grid. TEM observations were performed with a Philips CM300ST microscope $\left(\mathrm{LaB}_{6}, 300 \mathrm{kV}\right)$ equipped with a F416 TVIPS CMOS camera and a Bruker Silicon Drift EDX (Energy Dispersive X-ray Spectroscopy) detector. Due to the high electron beam sensitivity of the material, this analysis was performed with a wide spread beam in spot size 5 to avoid its degradation. Under these 
conditions, it was impossible to work in conventional zone axis ED or manual 3D ED. Consequently, the crystal structure determination of $\mathrm{Na}_{2} \mathrm{VO}\left(\mathrm{HPO}_{4}\right)_{2}$ required a faster method to record a complete dataset, such as continuous 3D ED. This experiment was performed using a single tilt tomography sample holder with a maximum tilt range of $-55^{\circ} /+53^{\circ}$. The datasets were collected by recording a video in ED mode during the continuous sample holder tilt, with a very spread electron beam in order not to damage the studied particle. A $2.2 \mu \mathrm{m}$ diameter Selected Area aperture was chosen to keep the isolated particle of interest inside despite its drift during the whole tilt process (Fig. 3). Before recording, a quick first tilt in image mode was performed to check if no other particle interfered during the automatic experiment. It is important to mention that, due to the very small angle step between each ED pattern that constitutes the recorded movie, no precession was applied during the experiment. Once the movie was recorded, an EDX analysis was performed on the particle to check if the three elements Na-V-P were still found in the ratio $\sim 2 / 1 / 2$ as expected from the nominal composition. This analysis was not possible before 3D ED due to the progressive decrease of the Na peak intensity during the spectrum acquisition, which requires a short acquisition time of approximately 30 seconds. The individual ED patterns were extracted by the video options of the camera software. Data processing was performed by PETS program ${ }^{25}$, which searches peaks on each ED pattern and produces a complete tridimensional representation of the reciprocal space. The JANA2006 sofware was used as a graphical interface to determine the unit cell and to refine the orientation matrix, which is thereafter used by PETS for the reflection intensities integration of each $\mathrm{ED}$ pattern ${ }^{26}$. Intensities belonging to the same reflection on adjacent patterns were integrated together, and a final list of intensities containing one value per each $h \mathrm{kl}$ indices with the corresponding estimated standard deviation was created. The crystal structure of $\mathrm{Na}_{2} \mathrm{VO}\left(\mathrm{HPO}_{4}\right)_{2}$ was solved by the charge flipping algorithm $^{27}$ using the Superflip program ${ }^{28}$ in the computing system JANA2006.

A scanning electron microscope (SEM) ZEISS SUPRA 55 with a resolution of about $1 \mathrm{~nm}$ was used for morphology studies. The sodium content was determined by atomic absorption spectroscopy with a Varian Spectra AA-20 instrument. The samples were dissolved in dilute $\mathrm{HNO}_{3}$ for chemical analysis. Thermogravimetric analysis (TGA) was performed in $\mathrm{N}_{2}$ atmosphere at heating rate of $2^{\circ} \mathrm{C} / \mathrm{min}$ (TMA 90, Setaram).

Sodium deintercalation into this phase has been carried out electrochemically using Swagelok type cells. The cells were assembled in an argon filled glove box, with sodium metal as the negative electrode and a borosilicate glass fiber sheet as separator and saturated with $1 \mathrm{M}$ $\mathrm{NaClO}_{4}$ in Propylene Cabonate (PC) for sodium cells. The composite positive electrode was prepared by mixing $80 \mathrm{wt} \%$ of active material, with $20 \mathrm{wt} \%$ of acetylene black. The electrochemical properties were monitored with a VMP II potentiostat/galvanostat (Biologic SA, Claix, France) at room temperature $\left(20{ }^{\circ} \mathrm{C}\right)$. Potentiostatic intermittent titration technique (PITT) measurements were conducted using potential steps of $10 \mathrm{mV}$ limited by a minimum current equivalent to a $\mathrm{C} / 100$ galvanostatic rate.

\section{Results and Discussion}

\section{Exchange of sodium for proton in $\mathrm{VO}\left(\mathrm{H}_{2} \mathrm{PO}_{4}\right)_{2}$ : the vanadophosphate $\mathrm{Na}_{2} \mathrm{VO}\left(\mathrm{HPO}_{4}\right)_{2}$}

The PXRD pattern of the exchanged phase $\mathrm{Na}_{2} \mathrm{VO}\left(\mathrm{HPO}_{4}\right)_{2}$ is shown on Fig. 1. In contrast to $\mathrm{VO}\left(\mathrm{H}_{2} \mathrm{PO}_{4}\right)_{2}$, where sharp diffraction peaks can be indexed in the space group P4/ncc, with a=8.967(6) $\AA, c=7.983(7) \AA$, we observe new reflections on the XRPD pattern 
after exchange, suggesting the formation of a new phase. Interestingly, the morphology between the two phases did not change considerably with the same bar like shape of about $2 \mu \mathrm{m}$ in length and $0.5 \mu \mathrm{m}$ for the height and breadth, suggesting a topotactic transformation with a strong relationship between the two phases (inset Fig. 1).

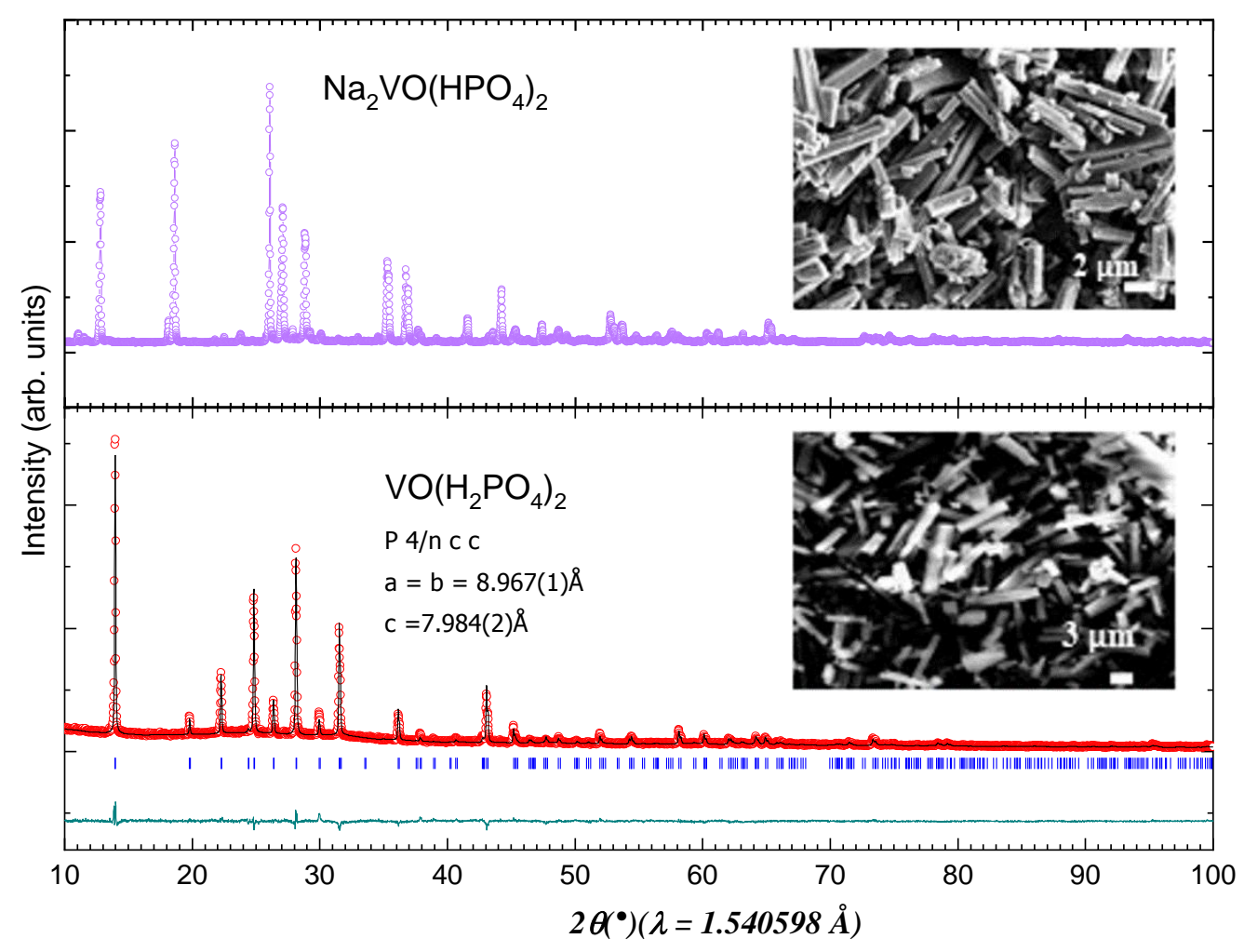

Fig. 1 XRD patterns of $\mathrm{VO}\left(\mathrm{H}_{2} \mathrm{PO}_{4}\right)_{2}$ and $\mathrm{Na}_{2} \mathrm{VO}\left(\mathrm{HPO}_{4}\right)_{2}$ and corresponding SEM images.

Attempts to determine $\mathrm{Na}_{2} \mathrm{VO}\left(\mathrm{HPO}_{4}\right)_{2}$ unit cell from XRPD pattern were unsuccessful, so the sample was investigated by TEM. Importantly, prior to the structural solution, one has to determine the exact chemical composition of this new phase. Thus, the sodium content was controlled by atomic absorption spectroscopy and an atomic ratio of 2:1:2 was found for Na:V:P. Thermogravimetric analysis (TGA) was performed under argon atmosphere in the temperature range $25-500^{\circ} \mathrm{C}$ (Fig. 2a). It shows a large weight loss at $250^{\circ} \mathrm{C}$ happening in one step and corresponding to the departure of one molecule of water. This is in agreement with the formation of the tetragonal phase $\beta-\mathrm{Na}_{2} \mathrm{VOP}_{2} \mathrm{O}_{7}$ (Fig. 2b) ${ }^{29}$ following the equation (3) :

$$
\mathrm{Na}_{2} \mathrm{VO}\left(\mathrm{HPO}_{4}\right)_{2(\mathrm{~s})} \rightarrow \beta-\mathrm{Na}_{2} \mathrm{VOP}_{2} \mathrm{O}_{7}(\mathrm{~s})+\mathrm{H}_{2} \mathrm{O}_{(\mathrm{v})}
$$

This reaction is associated with a large exothermic peak on the DSC curve and characterizes the structural transformation. These chemical analyses confirmed the ion exchange phase composition $\left(\mathrm{Na}_{2} \mathrm{H}_{2} \mathrm{VP}_{2} \mathrm{O}_{9}\right)$. Note therefore an additional exothermic peak at $180^{\circ} \mathrm{C}$, which is not associated to a weight loss but correspond to the beginning of the water departure and could also be associated to the presence of impurities or a small structural arrangement suggesting the presence of structural disorder in the material. 


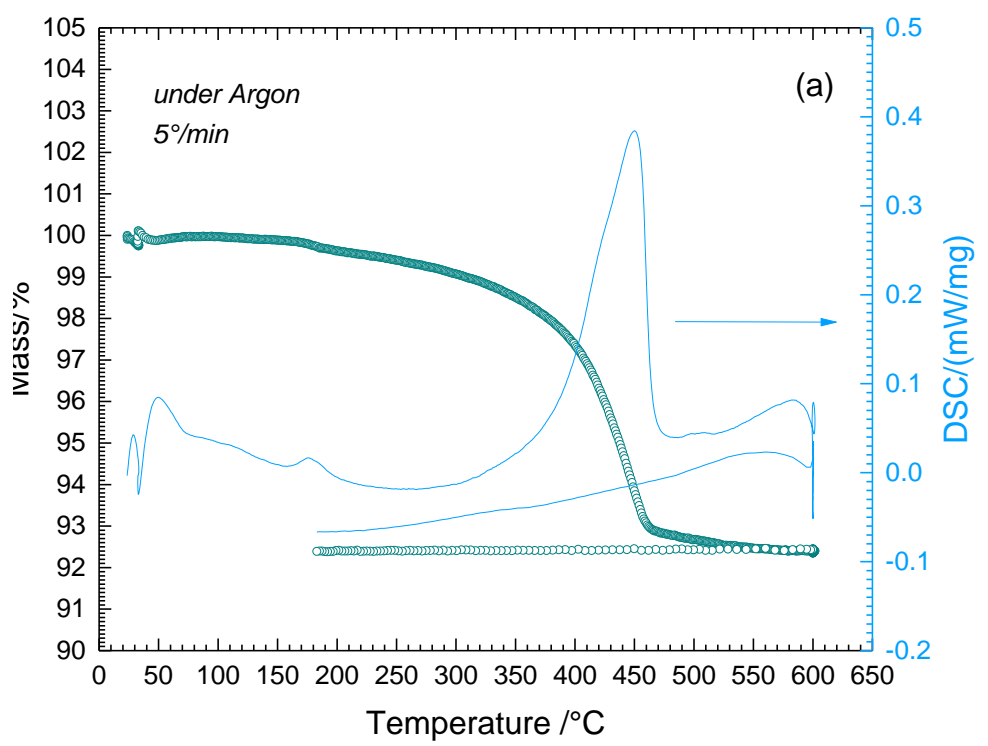

(a)

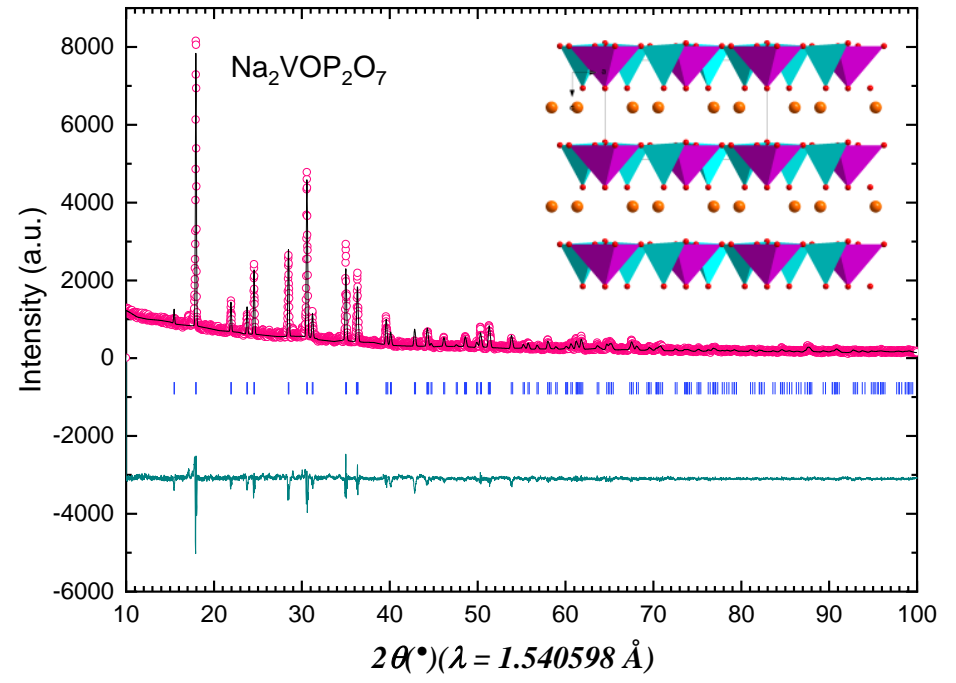

(b)

Fig. 2 (a)TGA-DSC curve of $\mathrm{Na}_{2} \mathrm{VO}\left(\mathrm{HPO}_{4}\right)_{2}$ under argon at $5 \% \mathrm{~min}$, (b) XRD pattern of the phase $\mathrm{Na}_{2} \mathrm{VOP}_{2} \mathrm{O}_{7}$ obtained after the TGA heat treatment at $600^{\circ} \mathrm{C}$, inset: structural view of tetragonal $\mathrm{Na}_{2} \mathrm{VOP}_{2} \mathrm{O}_{7}$.

Despite several attempts, we never succeeded in completely exchanging all protons with sodium. In contrast to the lithium exchange ${ }^{30}$, only $50 \%$ of protons could be exchanged with sodium, due to the larger size of $\mathrm{Na}^{+}$compared to $\mathrm{Li}^{+}$, as it will be shown further. Curiously, ionic exchange with $\mathrm{NaBr}$ or $\mathrm{NaCl}$ did not allow us to form any kind of sodium/vanadophosphate.

\section{First structural model from Electron Diffraction study}


Three continuous 3D ED datasets were recorded on three different particles of the phase $\mathrm{Na}_{2} \mathrm{VO}\left(\mathrm{HPO}_{4}\right)_{2}$ at different tilt speeds; in order to observe eventual effects of this parameter on the structure solutions. The three data collections started at a fixed angle, and finished by stopping manually and simultaneously the tilt and the movie recording when the tilt limit was reached, which happened around $-55^{\circ}$. The experimental conditions (acquisition time, number of ED patterns extracted from the videos and angle step) are detailed in Table 1.

\begin{tabular}{lccc}
\hline \hline & experiment 1 & experiment 2 & experiment 3 \\
\hline Start angle & $54^{\circ}$ & $53^{\circ}$ & $53^{\circ}$ \\
\hline End angle & $-54.59^{\circ}$ & $-54.78^{\circ}$ & $-55.26^{\circ}$ \\
\hline Acquisition time & $1 " 59^{\prime}$ & $3 " 38^{\prime}$ & $3^{\prime \prime} 57^{\prime}$ \\
\hline Number of ED patterns & 251 & 456 & 397 \\
\hline Angle increment & $0.43^{\circ}$ & $0.24^{\circ}$ & $0.27^{\circ}$ \\
\hline \hline
\end{tabular}

Table 1 Experimental acquisition conditions on three different particles of $\mathrm{Na}_{2} \mathrm{VO}\left(\mathrm{HPO}_{4}\right)_{2}$.

The EDX analyses performed after each acquisition on the three particles revealed cationic ratios close to the Na:2 V:1 P:2 expected stoichiometry, so the three datasets are considered as suitable for the structure determination. After reflections search and the 3D reconstruction of the reciprocal space by PETS software, the most symmetrical unit cell was calculated with the following cell parameters averaged from the three datasets: $\mathbf{a} \approx \mathbf{b} \approx 14.3$ $\AA, \mathbf{c} \approx 7.7 \AA$, and the three angles $\alpha, \beta, \gamma$ are close to $90^{\circ}$. Due to the low precision in the cell parameter values, it was impossible to make a difference between an orthorhombic and a tetragonal unit cell, so the tetragonal crystal system, which is most symmetrical, was chosen at this stage of the study. The extinction conditions were determined from several selected sections of the reciprocal space generated by PETS after reflection intensities extraction. The indexation of theses sections (Fig. 3) leads to the following extinction conditions: $h k l: \mathrm{h}+\mathrm{k}+\mathrm{l}$ $=2 \mathrm{n}, O k l: \mathrm{k}, 1=2 \mathrm{n}, h k 0: \mathrm{h}+\mathrm{k}=2 \mathrm{n}, h h l: 1=2 \mathrm{n}$, which are consistent with the tetragonal space group $I 4 / \mathrm{mcm}(140)$. 


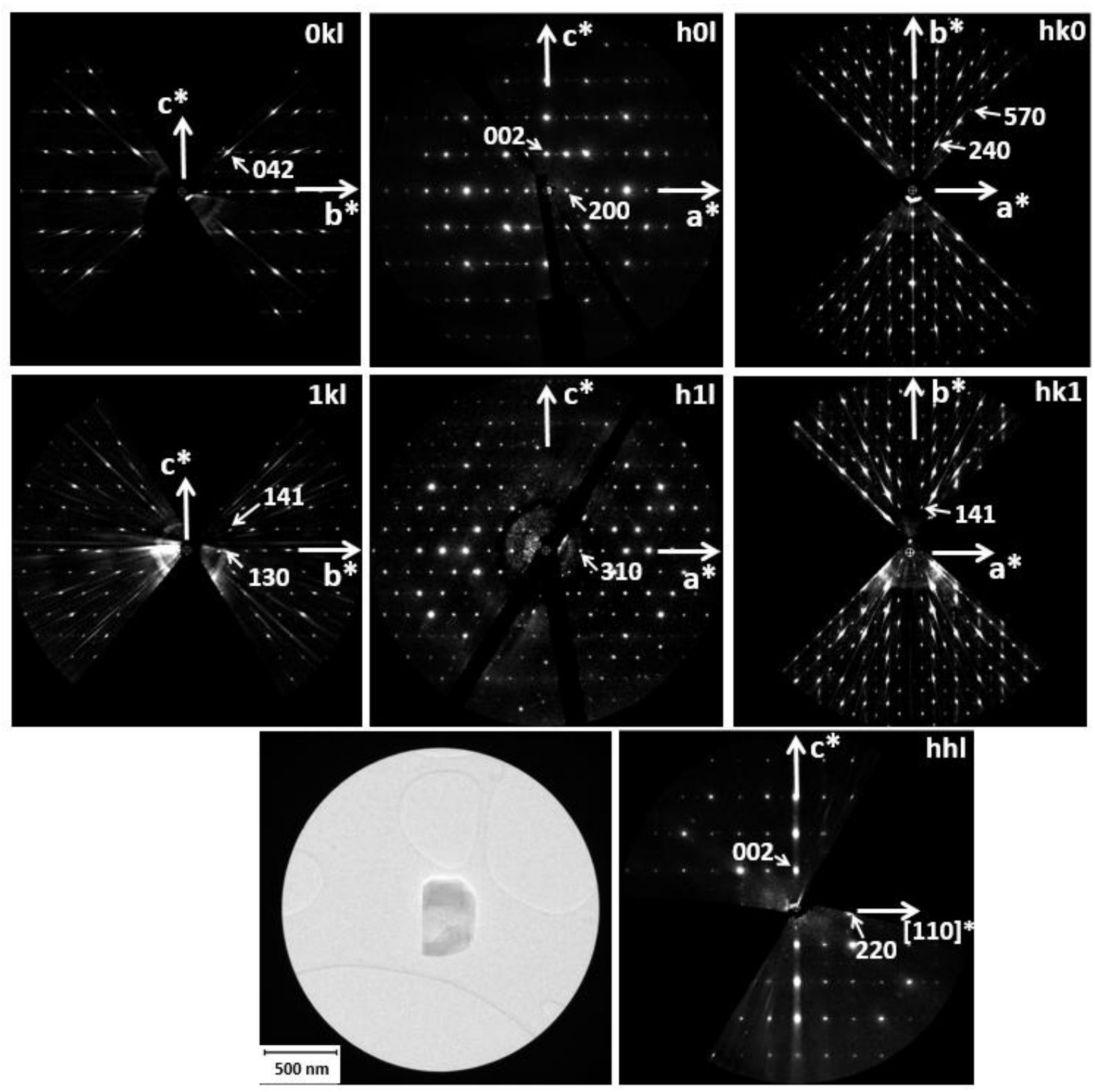

Fig. 3 Selected sections of the reciprocal space indexed in $14 / \mathrm{mcm}$ space group of $\mathrm{Na}_{2} \mathrm{VO}\left(\mathrm{HPO}_{4}\right)_{2}$ and at the bottom left : image of one crystallite with the Selected Area aperture used for the 3D ED data collection.

The datasets from the three experiments were then processed by Superflip in JANA2006 program. The symmetry analysis confirmed the space group revealed by the study of the reciprocal space sections, since symmetry tests carried out in I $4 / \mathrm{mmm}$ and $I 4 / \mathrm{mcm}$ space groups show $\mathrm{R}_{\text {int }}$ values (intensity difference among the symmetry related reflections) slightly lower in $\mathrm{I} 4 / \mathrm{mcm}$, with better redundancies, for the three experiments (Table 2). $A b$ initio structure calculations with charge flipping algorithm were performed on the three datasets, and the resulting reliability factors, numbers of independent reflections and completeness at $0.6 \AA$ resolution value are summarized in Table 2 . 


\begin{tabular}{|c|c|c|c|c|}
\hline & & experiment 1 & experiment 2 & experiment 3 \\
\hline \multirow[t]{2}{*}{ Symmetry test : I4/mmm } & $\mathrm{R}_{\mathrm{int}}$ & $34.59 \%$ & $36.48 \%$ & $45.36 \%$ \\
\hline & Redundancy & 7.324 & 7.308 & 7.426 \\
\hline \multirow[t]{2}{*}{ Symmetry test : I4/mcm } & $\mathrm{R}_{\text {int }}$ & $34.47 \%$ & $36.01 \%$ & $45.17 \%$ \\
\hline & Redundancy & 7.529 & 7.551 & 7.57 \\
\hline \multirow[t]{3}{*}{ Superflip results } & Number of independant reflections & 415 & 406 & 401 \\
\hline & Completeness at $0.6 \AA$ & $100 \%$ & $99.6 \%$ & $98.7 \%$ \\
\hline & $\mathrm{R}_{\text {overall }}$ & $23.65 \%$ & $24.65 \%$ & $22.22 \%$ \\
\hline
\end{tabular}

Table 2 After treatment of the datasets from the three experiments: $R_{\text {int }}$ and Redundancy values after $\mathrm{I} 4 / \mathrm{mmm}$ and $\mathrm{I} / \mathrm{mcm}$ space group tests, number of independent reflections, completeness and $\mathrm{R}_{\text {overall }}$ values after Superflip calculations.

The calculations of structural model for the three datasets converge to the same electron density maps, which confers a good confidence in the reliability of the model. The 3D electron density map from the experiment 1 is presented in Fig. 4 as a [001] projection. However, the occupations by atoms are different, which means an incorrect interpretation by JANA2006 in term of positioning chemical species within the electron densities. The only cationic positions that remain identical between structural models from each dataset are vanadium positions, which may be explained by a value of diffuse scattering factor by electrons for $\mathrm{V}$ almost twice as big as those of sodium and phosphorus ${ }^{31}$. Thus vanadium positions are considered as correct.

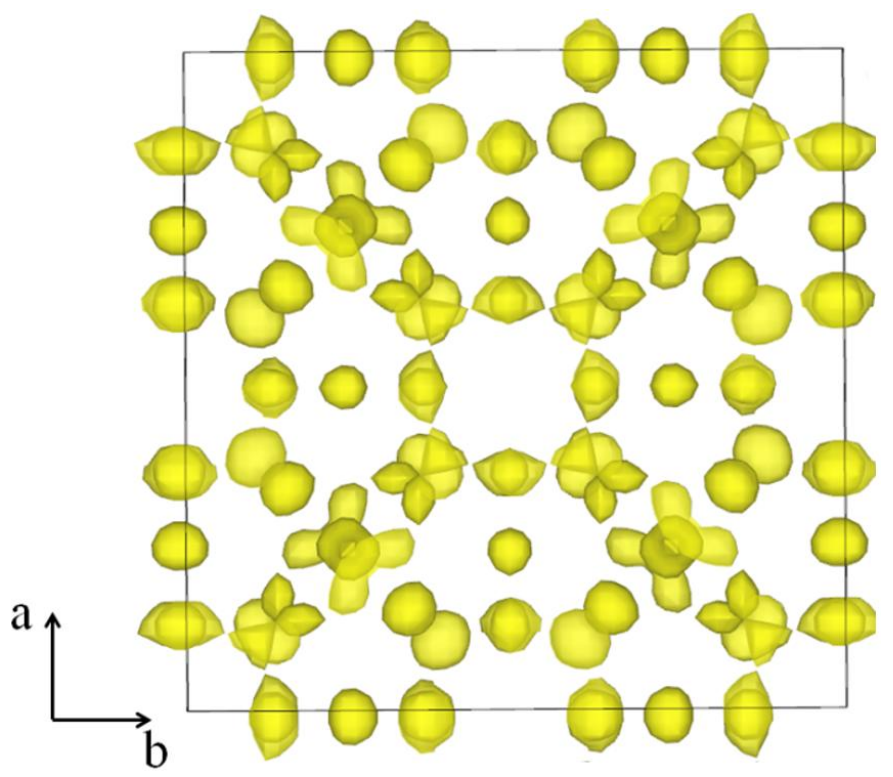

Fig. 4 [001] Electrostatic potential isosurface of structure solution in $14 / \mathrm{mcm}$ after Superflip calculations from experiment 1 dataset.

The attribution of proper chemical species to each atomic position was carried out by comparing interatomic distances with the theoretical ones listed in the Shannon Tables ${ }^{32}$. Cation-oxygen distances were then expected to be around $2.6 \AA$ between Na and O, $2.0 \AA$ between $\mathrm{V}$ and $\mathrm{O}$ and $1.6 \AA$ between $\mathrm{P}$ and $\mathrm{O}$. Furthermore, based on analogous vanadate phosphate structures from literature, $\mathrm{P}$ and $\mathrm{V}$ atoms are expected to be respectively in 
tetrahedral and octahedral environments. These crystal chemistry considerations give rise to the resulting structural model in Fig. 5a and 5b. The model still exhibits two discrepancies : the corresponding chemical formulation is $\mathrm{Na}_{2} \mathrm{VP}_{3} \mathrm{O}_{12}$ instead of the expected $\mathrm{Na}_{2} \mathrm{VP}_{2} \mathrm{O}_{9}$, and the $\mathrm{O}-\mathrm{O}$ distances in the basal plane of the $\mathrm{V}$ polyhedron are between $1.34 \AA$ and $1.64 \AA$, whereas theoretical O-O distances should be over $2.5 \AA$ according to the Shannon Tables ${ }^{32}$. Thus the structural model that will be used as input for the structure refinement from PXRD pattern considers only one half of the $\mathrm{O}$ atoms in the basal plane of the $\mathrm{V}$ polyhedron in order to get a regular octahedron, and one half of $\mathrm{P} 2$ atomic positions (Fig. 5b), in order to reach the expected chemical formulation $\mathrm{Na}_{2} \mathrm{VP}_{2} \mathrm{O}_{9}$.

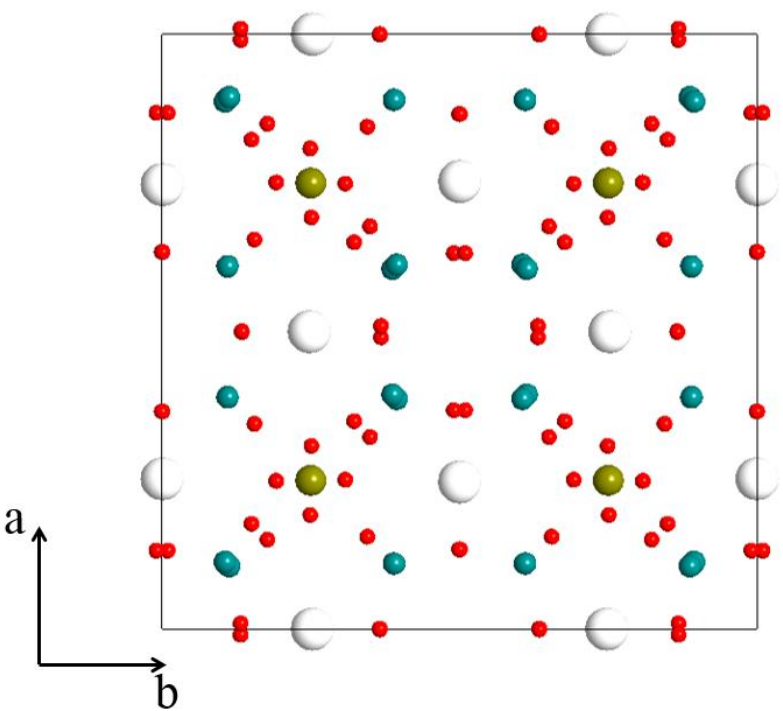

(a)

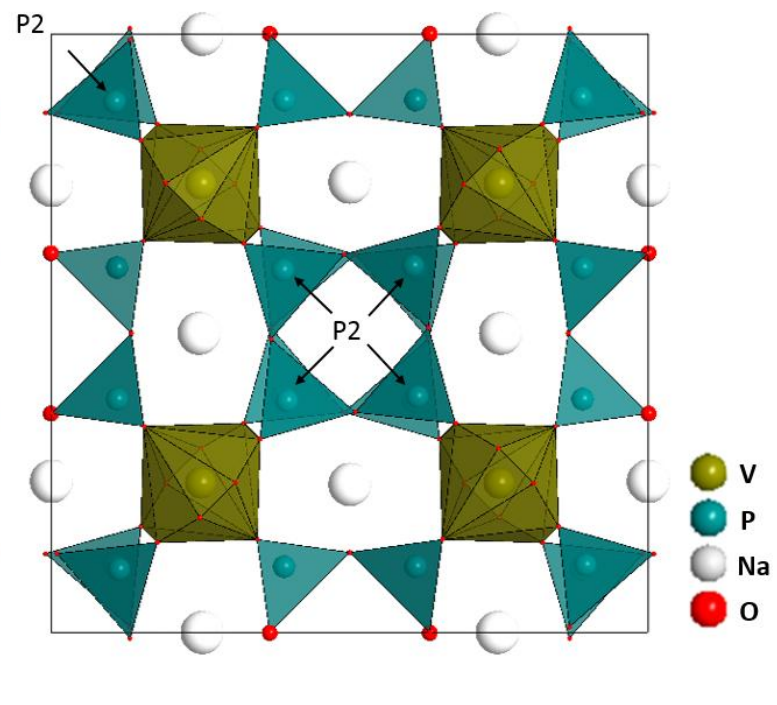

(b)

Fig. 5 (a) Structural model in $I 4 / \mathrm{mcm}$ space group after having placed correctly chemical species in the crystallographic sites and (b) with $\mathrm{V}$ and $\mathrm{P}$ polyhedra.

\section{Powder X-ray diffraction refinement}

In order to confirm the $I 4 / \mathrm{mcm}\left(\mathrm{n}^{\circ} 140\right)$ tetragonal structure found by electron diffraction, some powder X-ray diffraction experiments were performed. When feeding the electron diffraction structure model in Fullprof ${ }^{23}$, and after correcting roughly the lattice parameters, it was difficult to validate the proposed structural model since too many refinement residues or unexplained peaks remained (Fig. 6). Although we know there are impurities in the powder, the possibility of a large impurity phase explaining these discrepancies was rejected after some considerations: first we were unable to find an impurity phase that would really improve the refinement, second, no trace of that phase was actually found in EDX analysis, and third, and most important, some peaks appear to be slightly doubled. These peaks arise in some different positions but more noticeably around the h00 or hk0 reflexions (Fig. 6 for examples on 200 and 420 reflexions respectively), leading us to believe an orthorhombic distortion was highly probable. 


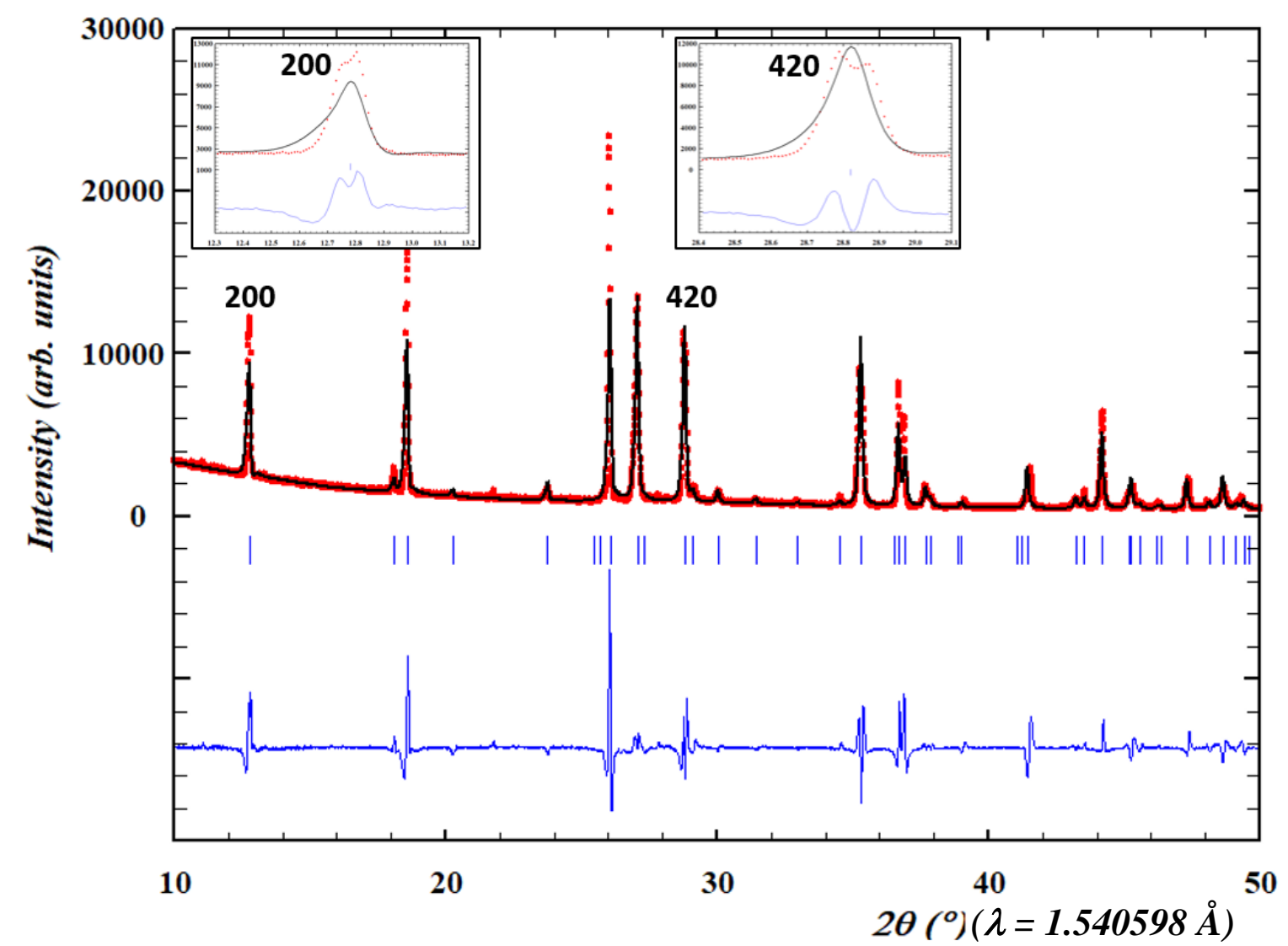

Fig. 6 LeBail refinement of the I4/mcm tetragonal unit cell from PRXD. Enlargements of 200 and 420 diffraction peaks show slight splits consistent with a possible orthorhombic distortion.

In consequence, as a lower symmetry was expected, an orthorhombic unit cell was defined in a Ibam (72) space group, consistent with the extinction conditions found by electron diffraction $(h k l: \mathrm{h}+\mathrm{k}+1=2 \mathrm{n}, O k l: \mathrm{k}, 1=2 \mathrm{n}, h O l: \mathrm{h}, 1=2 \mathrm{n}, h k 0: \mathrm{h}+\mathrm{k}=2 \mathrm{n})$. These information were then fed back into Superflip which resulted in a new structure, almost identical to the previous one, but with regular octahedral environment for vanadium and an associated chemical formula $\mathrm{Na}_{2} \mathrm{VP}_{2} \mathrm{O}_{9}$. The transition to a lower symmetry improved significantly the refinement, however leaving some peaks not satisfactorily explained, especially low index peaks like 200, 020 and 420. Checking on the structural model, it can be found these planes contain Vanadium and Sodium atoms, all in specific position. Furthermore, thermal parameters, when refined, are taking unusually high values. The structure seems too constrained. Consequently, a lower symmetry model, presenting the same systematic extinctions, was tried with Iba2 (45) space group, letting Vanadium and Sodium atoms being on a general position. A strong improvement of the refinement is then observed (differences on refinements with Ibam and Iba2 space groups are displayed on Fig. 7a). The final Rietveld refinement on Fig. $7 \mathrm{~b}$ still exhibits small misfits and quite high $\mathrm{R}$ values $\left(\mathrm{Rp}=9.94 \%, \mathrm{Rwp}=14.4 \%, \mathrm{R}_{\mathrm{Bragg}}=28.8 \%\right.$ ), which are mainly attributed to the small impurities peaks in the foot of the main (321) peak as well as a shoulder on the (202) peak. Finally, checking on the structural model, only an oxygen atom (O8, probably affected by the shoulder 
on the (202) peak) is found to be slightly out of position and relocated on an acceptable position without noticeable influence on the rest of the refinement.

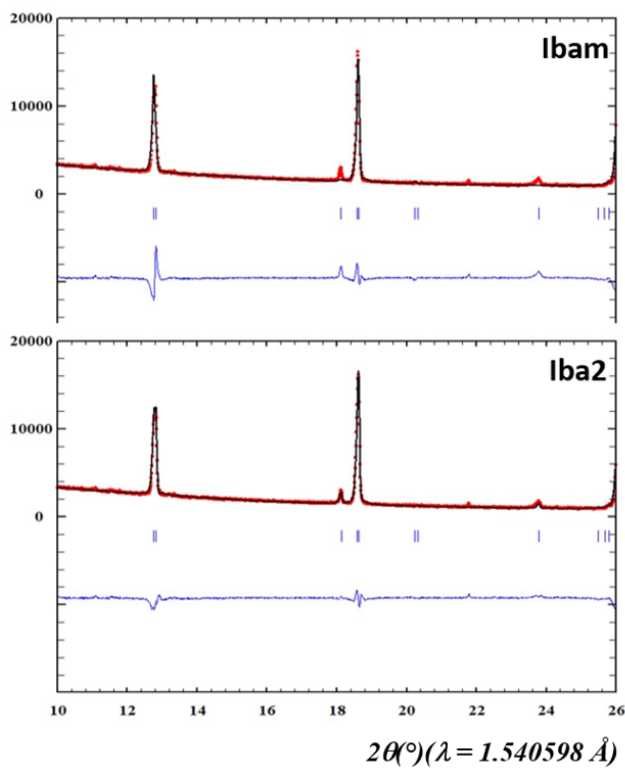

(a)

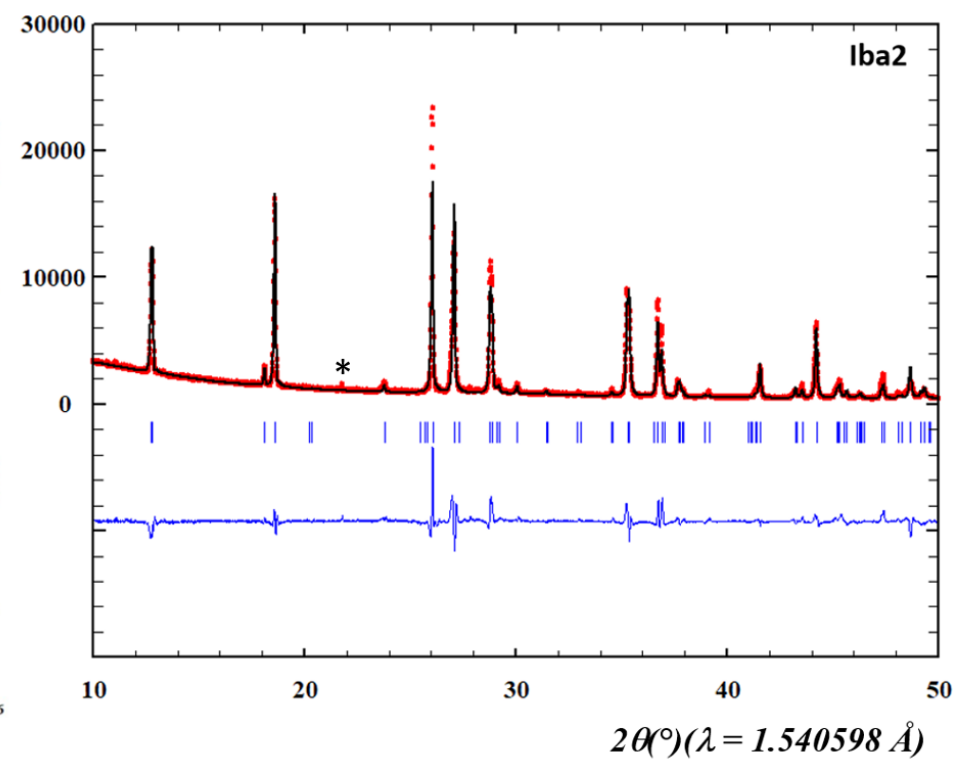

(b)

Fig. 7 (a) Comparison between Ibam and Iba2 Rietveld refinement, (b) final PXRD pattern of $\mathrm{Na}_{2} \mathrm{VO}\left(\mathrm{HPO}_{4}\right)_{2}$ after Rietveld refinement. The asterisk refers to an impurity diffraction peak.

Attempts to highlight hydrogen positions using Fast Fourier Difference maps were unsuccessful due to the numerous residual weak electron densities peaks. Then, the most likely $\mathrm{H}$ positions in the structure were suggested by crystal chemistry and crystallographic considerations, leading to the final model depicted in Fig. 8.

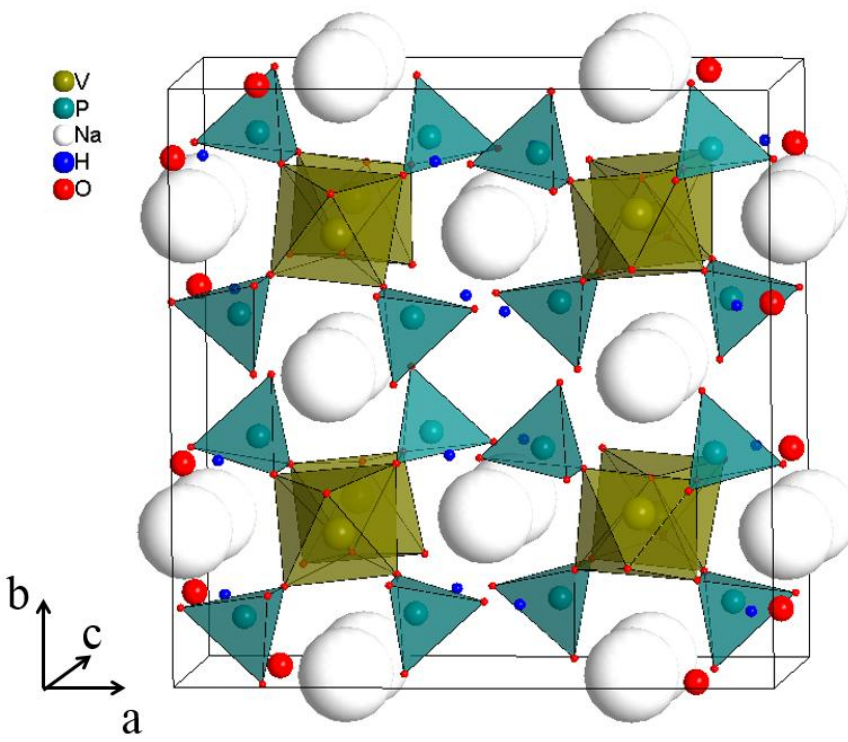

(a)

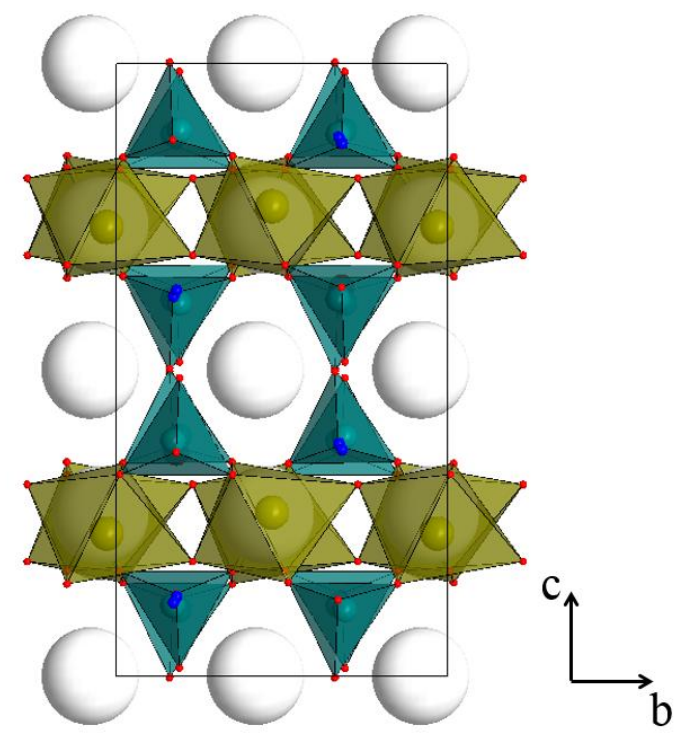

(b) 
Fig. 8 (a) Refined structure of $\mathrm{Na}_{2} \mathrm{VO}\left(\mathrm{HPO}_{4}\right)_{2}$ with $\mathrm{H}$ positions deduced from crystal chemistry and (b) its [100] projection.

Refined cell parameters and atomic positions are listed in Tables 3. For further validating the crystallographic structure, cation-oxygen distances were examined (Table 4). Vanadium, which is in octahedral environment, displays six different V-O distances ranged between $1.86 \AA$ and $2.1 \AA$. Phosphorus atoms P1 and P2 are in tetrahedral environments, surrounded by three oxygen atoms and one $\mathrm{OH}$ group, with distances ranged between $1.45 \AA$ and $1.7 \AA$. All these distances are consistent with those predicted by the Shannon tables ${ }^{32}$. The final crystal structure of $\mathrm{Na}_{2} \mathrm{VO}\left(\mathrm{HPO}_{4}\right)_{2}$ has been deposited to the Cambridge Crystallographic Data Center (CCDC), and its deposition number is 2089416.

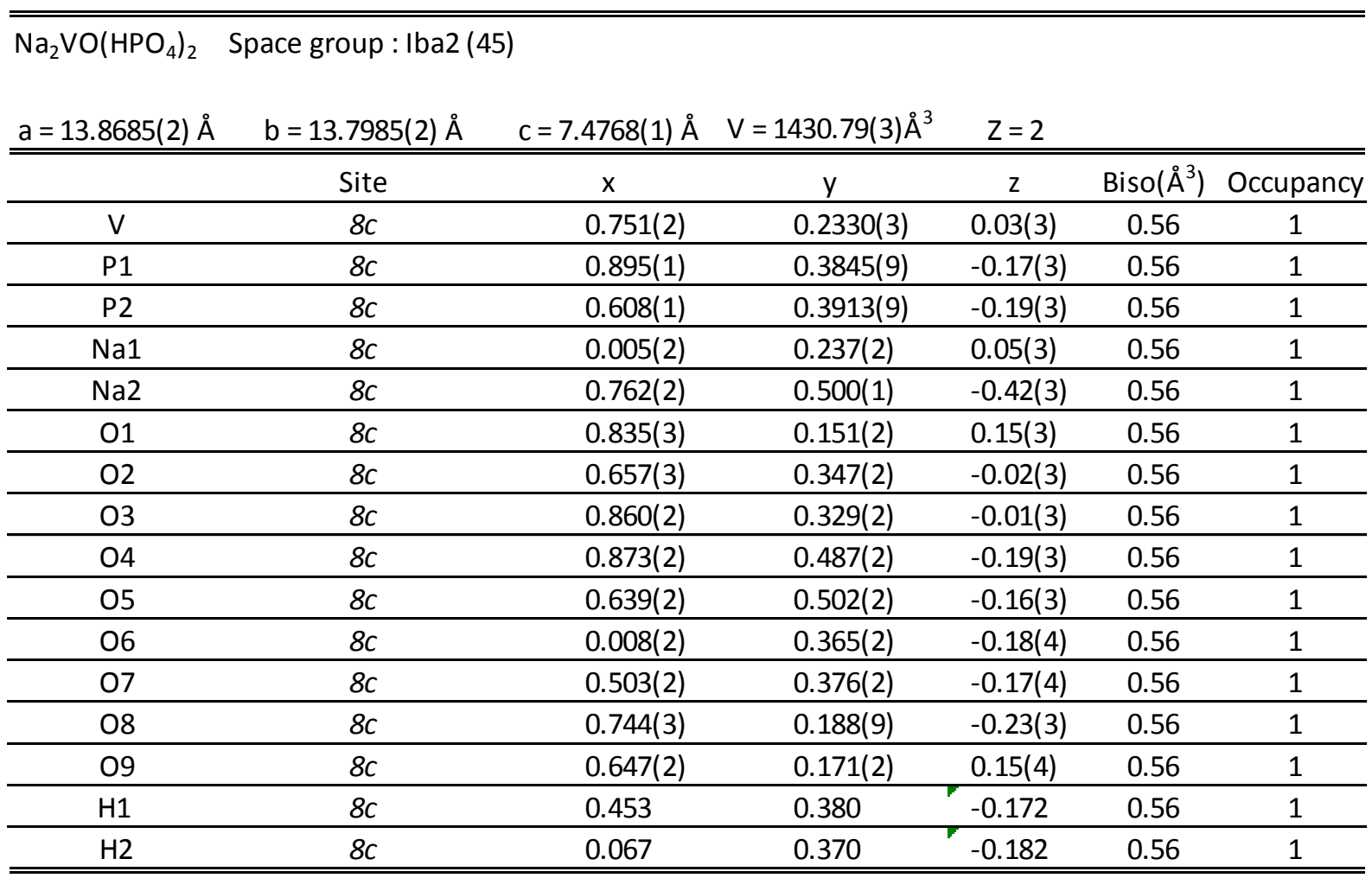

Table 3 Crystallographic parameters of $\mathrm{Na}_{2} \mathrm{VO}\left(\mathrm{HPO}_{4}\right)_{2}$ deduced from PXRD Rietveld refinement at room temperature. 


\begin{tabular}{|c|c|c|}
\hline \multirow[t]{6}{*}{ V } & 01 & $1.86(16)$ \\
\hline & 02 & $2.08(7)$ \\
\hline & 03 & $2.04(6)$ \\
\hline & 08 & $2.0(3)$ \\
\hline & 08 & $2.1(3)$ \\
\hline & 09 & $1.90(18)$ \\
\hline \multirow[t]{4}{*}{ P1 } & O3 & $1.5(3)$ \\
\hline & $\mathrm{O} 4$ & $1.45(4)$ \\
\hline & 06 & $1.60(4)$ \\
\hline & 09 & $1.7(3)$ \\
\hline \multirow[t]{4}{*}{ P2 } & 01 & $1.5(2)$ \\
\hline & $\mathrm{O} 2$ & $1.6(3)$ \\
\hline & 05 & $1.61(5)$ \\
\hline & 07 & $1.48(5)$ \\
\hline
\end{tabular}

\begin{tabular}{|c|c|c|}
\hline \multirow[t]{5}{*}{$\mathrm{Na1}$} & $\mathrm{O} 2$ & $2.46(8)$ \\
\hline & $\mathrm{O} 3$ & $2.42(7)$ \\
\hline & 06 & $2.5(3)$ \\
\hline & 07 & $2.3(3)$ \\
\hline & 09 & $2.46(12)$ \\
\hline \multirow[t]{2}{*}{$\mathrm{Na} 2$} & 04 & $2.3(2)$ \\
\hline & 05 & $2.5(2)$ \\
\hline
\end{tabular}

Table 4 Cation-oxygen distances in $\mathrm{Na}_{2} \mathrm{VO}\left(\mathrm{HPO}_{4}\right)_{2}$ after Rietveld refinement from PXRD data.

The possibility to de-intercalate sodium vs $\mathrm{Na}^{+} / \mathrm{Na}$ was investigated (Fig. 9) and we found that only 0.66 sodium could be extracted up to $4.3 \mathrm{~V} \mathrm{vs} \mathrm{Na}^{+} / \mathrm{Na}$ in the course of the first charge through a solid solution process. Due to the defects, the sodium diffusion is rather difficult then the electrochemical performance of this material was not investigated further.

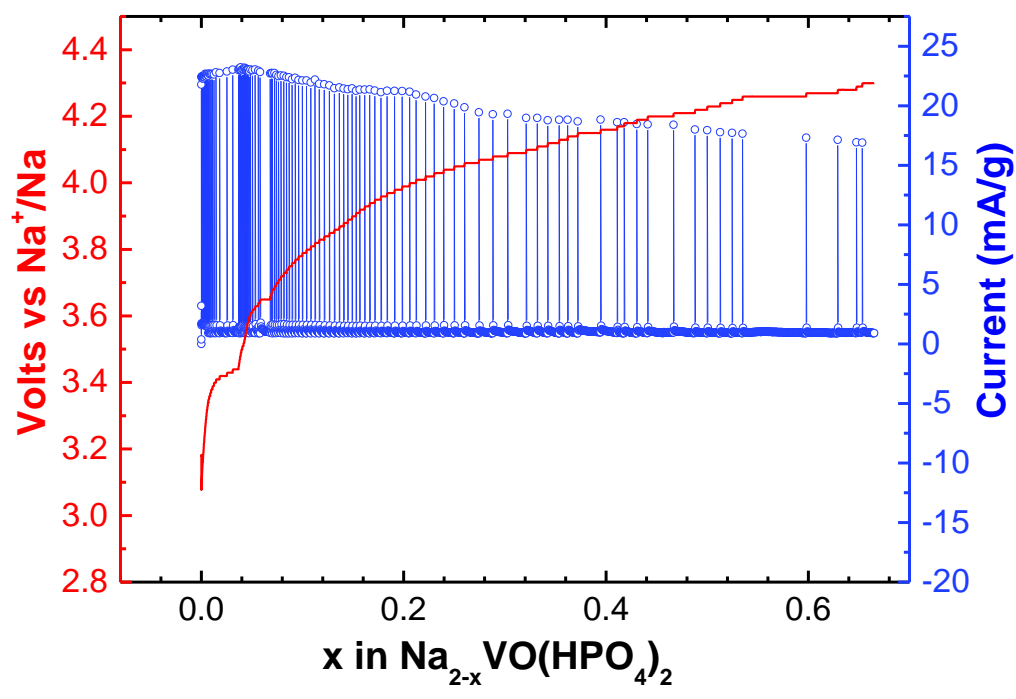

Fig. 9 Potentiometric titration curve (PITT) for $\mathrm{Na}_{2} \mathrm{VO}\left(\mathrm{HPO}_{4}\right)_{2}$ in the range of $4.3-3.0 \mathrm{~V}$ vs $\mathrm{Na}^{+} / \mathrm{Na}$ using $5 \mathrm{mV}$ potential step in duration of $1 \mathrm{~h}$ and current limitation equivalent to a galvanic current $\mathrm{I}_{\text {limit }}=\mathrm{I}_{\mathrm{C} / 100}$. 


\section{Conclusions}

A new sodium vanadate phosphate $\mathrm{Na}_{2} \mathrm{VO}\left(\mathrm{HPO}_{4}\right)_{2}$ was synthesized, and its crystal structure was solved using continuous 3D ED combined with PXRD Rietveld refinement. The structural model from 3D ED evidenced a tetragonal unit cell, but the Rietveld refinement from PXRD data reveals a slight orthorhombic distortion, which was impossible to detect from ED data. Finally the structure is described with the cell parameters $a=13.86852(19)$, $\mathrm{b}=13.7985(2), \mathrm{c}=7.47677(9)$ in the Iba2 space group. Despite the poor electrochemical activities of $\mathrm{Na}_{2} \mathrm{VO}\left(\mathrm{HPO}_{4}\right)_{2}$, further synthetic efforts are needed to obtain a new vanadium phosphate with a reversible electrochemical activity as well as trying to exchange completely the proton from the structure.

CSD Number 2089416.

\section{Acknowledgments}

The authors gratefully acknowledge S. Eichendorff, M. Freire, E. Anger and E. Adamczyk for technical help and discussion. C. Lepoittevin acknowledges Dr Stéphanie Kodjikian for the fruitful discussions about the structure. V. Pralong thanks the CNRS and the Indian-French Laboratory of Solid State Chemistry LAFICS for financial funding. E. Anger and V. Pralong gratefully acknowledges the Labex $\mathrm{EMC}^{3}$ and the Normandy region through the project $\mathrm{n}^{\circ} 16 \mathrm{E} 00581 / 16 \mathrm{P} 03273$. 


\section{References}

(1) C. Delmas, A. Nadiri and J. L. Soubeyroux, Solid State Ionics, 1988, 28-30, 419-423.

(2) Y. Uebou, T. Kiyabu, S. Okada and Yamaki, Rep. Inst. Adv. Mater. Study, 2002, 16, 1-5.

(3) D. Kundu, E. Talaie, V. Duffort and L. F. Nazar, Angew. Chem. Int. Ed., 2015, 54, 34313448.

(4) Y.-U. Park, D.-H. Seo, H.-S. Kwon, B. Kim, J. Kim, H. Kim, I. Kim, H.-I. Yoo and K. Kang, J. Am. Chem. Soc., 2013, 135, 13870.

(5) J. Zhao, L. Mu, Y. Qi, Y.-S. Hu, H. Liu and S. Dai, Chem. Commun., 2015, 51, 71607163.

(6) Y. R. Qi, L. Q. Mu, J. M. Zhao, Y.-S. Hu, H. Z. Liu and S. Dai, J. Mater. Chem. A, 2016, 4, 7178-7184.

(7) W. Deriouche, E. Anger, M. Freire, A. Maignan, N. Amdouni and V. Pralong, Solid State Sciences, 2017, 72, 124-129.

(8) P. Barpanda, G. D. Liu, M. Avdeev and A. Yamada, ChemElectroChem., 2014, 1, 14881491.

(9) S. Y. Lim, H. Kim, J. Chung, J. H. Lee, B. G. Kim, J. J. Choi, K. Y. Chung, W. Cho, S. J. Kim, W. A. Goddard, Y. Jung and J. W. Choi, Proc. Natl. Acad. Sci. U S A., 2014, 111, 599604.

(10) C. Deng and S. Zhang, ACS Appl. Mater. Interfaces, 2014, 6, 9111-9117.

(11) S. Ferdov, M. S. Reis, Z. Lin, R. A. Ferreira, Inorg. Chem., 2008, 47, 10062-10066.

(12) M. Schindler, W. Joswig, W.H. Baur, J. Solid State Chem., 1999, 145, 15-22.

(13) R. Vincent and P.A. Midgley, Ultramicroscopy, 1994, 53, 271-282.

(14) U. Kolb, T. Gorelik, C. Kubel, M. T. Otten and D. Hubert, Ultramicroscopy, 2007, 107, 507-513.

(15) C. Lepoittevin, J. Solid State Chem., 2016, 242, 228-235.

(16) P. Boullay, L. Palatinus and N. Barrier, Inorg. Chem., 2013, 52, 6127-6135.

(17) O. A. Drozhzhin, V. D. Sumanov, O. M. Karakulina, A. M. Abakumov, J. Hadermann, A. N. Baranov, K. J. Stevenson and E. V. Antipov, Electrochimica Acta, 2016, 191, 149-157.

(18) L. Palatinus, P. Brázda, P. Boullay, O. Perez, M. Klementová, S. Petit, V. Eigner, M. Zaarour and S. Mintova, Science, 2017, 355, 166-169. 
(19) G. Villeneuve, A. Erragh, D. Beltran, M. Drillon and P. Hagenmuller, Mat. Res. Bull., 1986, 21, 621-631.

(20) A. Le Bail, H. Duroy, J. L. Fourquet, Mat. Res. Bull., 1988, 23, 447-452.

(21) H. M. Rietveld, J. Appl. Crystallogr., 1969, 2, 65-71.

(22) P. Thompson, D. E. Cox and J. B. Hastings, J. Appl. Crystallogr., 1987, 20, 79-83.

(23) J. Rodriguez-Carvajal, Physica B, 1993, 192, 55-69.

(24) T. Roisnel and J. Rodriguez-Carvajal, Mater. Sci. Forum, 2001, 378-381, 118-123.

(25) L. Palatinus, Institute of Physics of the AS CR:Prague, Czechia, 2011.

(26) V. Petricek, M. Dusek and L. Palatinus, Z. Kristallogr., 2014, 229(5), 345-352.

(27) L. Palatinus, Acta Cryst., 2013, B66, 1-16.

(28) L. Palatinus and G. Chapuis, J. App. Cryst., 2007, 40, 786-790.

(29) V. Zima, L. Beneš, R. Šišková, P. Fatěna and J. Votinskỳ, Solid State Ionics, 1994, 67, 277-280.

(30) M. Satya Kishore, V. Pralong, V. Caignaert, U. V. Varadaraju and B. Raveau, Electrochem. Commun., 2006, 8, 1558-1562.

(31) International Tables for Crystallography Volume C : Mathematical, physical and chemical tables, 2006, 262-391.

(32) R. D. Shannon, Acta Cryst., 1976, A32, 751-767. 